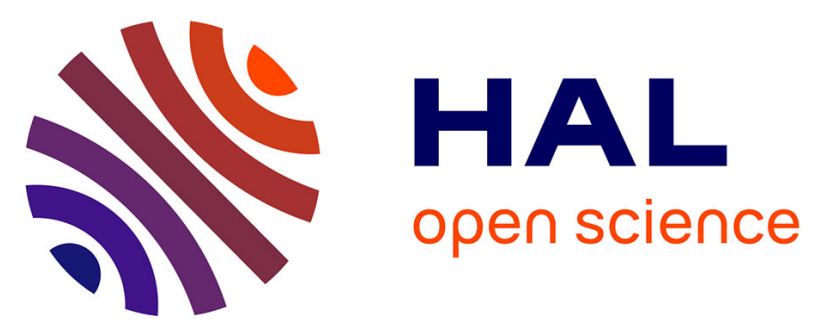

\title{
Laser-induced primary and secondary hemostasis dynamics and mechanisms in relation to selective photothermolysis of port wine stains
}

Michal Heger, Isabelle I. Salles, Rick Bezemer, Martijn A. Cloos, Serge R. Mordon, Sylvie Bégu, Hans Deckmyn, Johan F. Beek

\section{To cite this version:}

Michal Heger, Isabelle I. Salles, Rick Bezemer, Martijn A. Cloos, Serge R. Mordon, et al.. Laserinduced primary and secondary hemostasis dynamics and mechanisms in relation to selective photothermolysis of port wine stains. Journal of Dermatological Science, 2011, 63 (3), pp.139-147. 10.1016/j.jdermsci.2011.04.015 . hal-00782858

\section{HAL Id: hal-00782858 \\ https://hal.science/hal-00782858}

Submitted on 29 Jul 2021

HAL is a multi-disciplinary open access archive for the deposit and dissemination of scientific research documents, whether they are published or not. The documents may come from teaching and research institutions in France or abroad, or from public or private research centers.
L'archive ouverte pluridisciplinaire HAL, est destinée au dépôt et à la diffusion de documents scientifiques de niveau recherche, publiés ou non, émanant des établissements d'enseignement et de recherche français ou étrangers, des laboratoires publics ou privés. 


\title{
Laser-induced primary and secondary hemostasis dynamics and mechanisms in relation to selective photothermolysis of port wine stains
}

\author{
Michal Heger ${ }^{\text {a,b,c,*}, ~ I s a b e l l e ~ I . ~ S a l l e s ~}{ }^{\text {d,1 }}$, Rick Bezemer ${ }^{\mathrm{a}, 1}$, Martijn A. Cloos ${ }^{\text {a }}$, Serge R. Mordon ${ }^{\mathrm{e}}$, \\ Sylvie Bégu ${ }^{\mathrm{f}}$, Hans Deckmyn ${ }^{\mathrm{d}}$, Johan F. Beek ${ }^{\mathrm{a}}$
}

\author{
a Department of Biomedical Engineering and Physics, Academic Medical Center, University of Amsterdam, Amsterdam, The Netherlands \\ ${ }^{\mathrm{b}}$ Biochemistry of Membranes, Institute of Biomembranes, University of Utrecht, Utrecht, The Netherlands \\ ${ }^{c}$ Department of Experimental Surgery, Academic Medical Center, University of Amsterdam, Amsterdam, The Netherlands \\ ${ }^{\mathrm{d}}$ Laboratory for Thrombosis Research, Interdisciplinary Research Center, Catholic University of Leuven at Kortrijk, Kortrijk, Belgium \\ ${ }^{\mathrm{e}}$ UPRES EA 2689 INSERM-IFR 114, Lille University Hospital, Lille, France \\ ${ }_{\mathrm{f}}^{\mathrm{T}}$ Technical Laboratory for Industrial Pharmacology, University of Montpellier, Montpellier, France
}

\begin{abstract}
Background: Superficial vascular anomalies such as port wine stains are commonly treated by selective photothermolysis (SP). The endovascular laser-tissue interactions underlying SP are governed by a photothermal response (thermocoagulation of blood) and a hemodynamic response (thrombosis). Currently it is not known whether the hemodynamic response encompasses both primary and secondary hemostasis, which platelet receptors are involved, and what the SP-induced thrombosis kinetics are in low-flow venules.

Objectives: To (1) define the role and kinetics of primary and secondary hemostasis in laser-induced thrombus formation and (2) determine which key platelet surface receptors are involved in the hemodynamic response.

Methods: 532-nm laser-irradiated hamster dorsal skin fold venules were studied by intravital fluorescence microscopy following fluorescent labeling of platelets with 5(6)-carboxyfluorescein. Heparin and fluorescently labeled anti-glycoprotein Ib- $\alpha$ (GPIb $\alpha)$ and anti-P-selectin antibodies were administered to investigate the role of coagulation and platelet receptors, respectively. Lesional sizes were quantified by software.

Results: Laser irradiation consistently produced sub-occlusive thermal coagula. Thrombosis was triggered in all irradiated venules in a thermal coagulum-independent manner and peaked at 6.25 min post-irradiation. Heparin decreased the maximum thrombus size and caused thrombosis to reach a maximum at $1.25 \mathrm{~min}$. Immunoblocking of GPIb $\alpha$ abated the extent of thrombosis, whereas immunoblocking of P-selectin had no effect.

Conclusions: The hemodynamic response ensues the photothermal response in a thermal coagulumindependent manner and involves primary and secondary hemostasis. Primary hemostasis is mediated by constitutively expressed GPIb $\alpha$ but not by activation-dependent P-selectin.
\end{abstract}

\section{Introduction}

Selective photothermolysis (SP) is a standard treatment modality for superficial vascular anomalies such as port wine stains (PWS) and other vessel-related dermatological disorders [1]. $\mathrm{SP}$ is based on the conversion of radiant energy to heat by

\footnotetext{
* Corresponding author at: Department of Experimental Surgery (IWO-1 IA1.131), Academic Medical Center, University of Amsterdam, Meibergdreef 9, 1105 AZ Amsterdam, The Netherlands. Tel.: +31 20 5665573; fax: +31 206976621.

E-mail address: M.Heger@amc.uva.nl (M. Heger).

1 These authors contributed equally to this work.
}

(de)oxyhemoglobin and the thermal denaturation of blood and vascular tissue as a result of heat diffusion, referred to as photocoagulation or the photothermal response. By employing an appropriate wavelength and irradiance, supracritical temperatures $\left(>70^{\circ} \mathrm{C}\right)$ can be generated in the vessel lumen and confined spatially when the pulse duration is shorter than the time required for cooling of the target structures [2], i.e., $0.5-10 \mathrm{~ms}$ for PWS vessels of $30-300 \mu \mathrm{m}$ in diameter [3,4]. Normal-sized capillaries and post-capillary venules (4-26 $\mu \mathrm{m}$ inner diameter [5]) have relatively short thermal relaxation times and thus remain spared during longer pulse durations, inasmuch as heat diffusion from these vessels precludes the generation of supracritical temperatures. 


\section{CONVENTIONAL PHOTOTHERMOLYSIS}
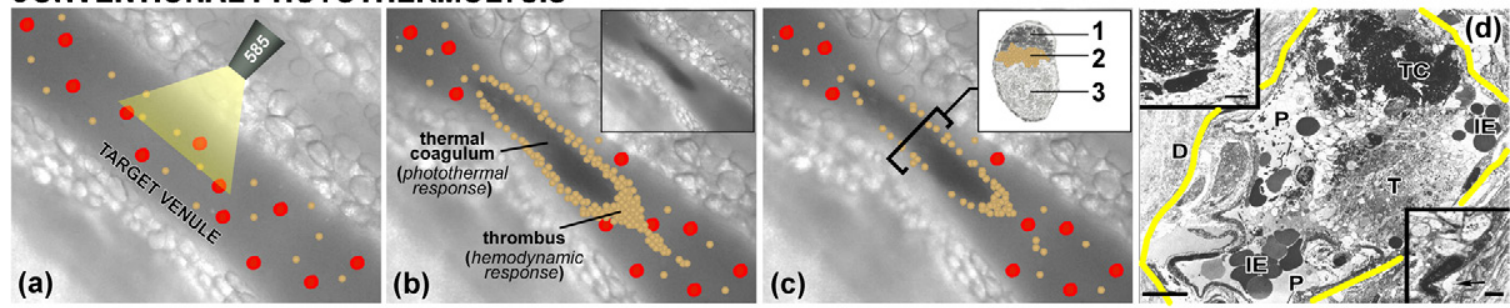

\section{SITE-SPECIFIC PHARMACO-LASER THERAPY}
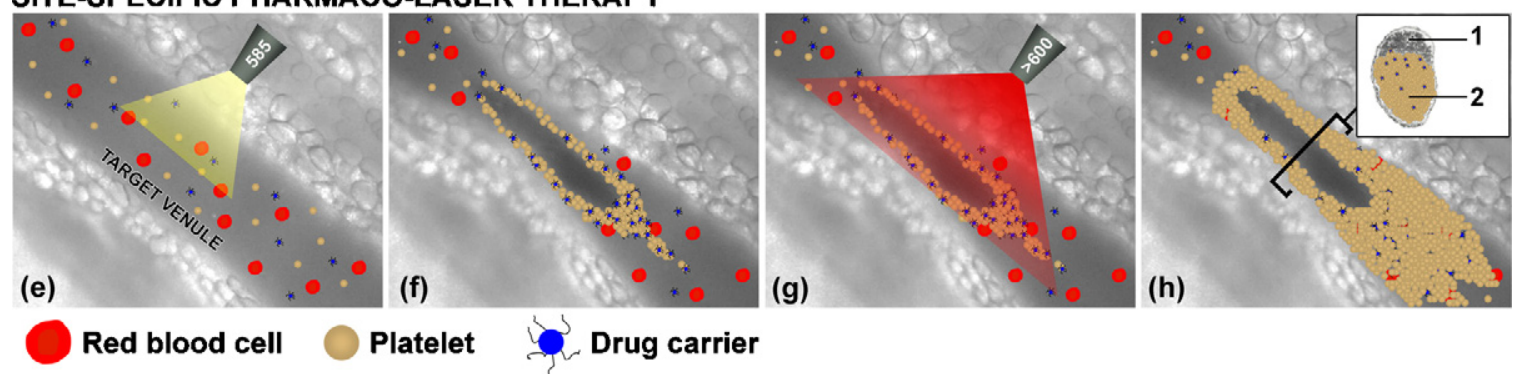

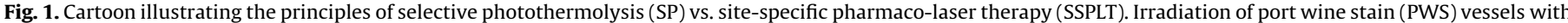

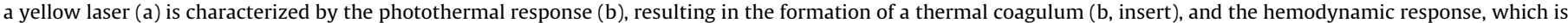

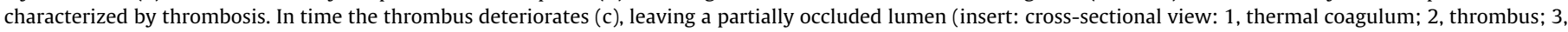

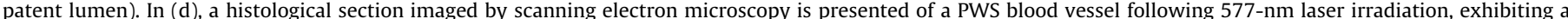

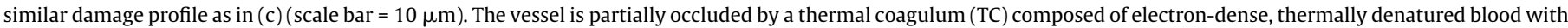

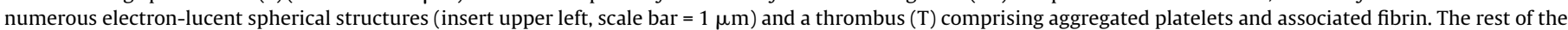

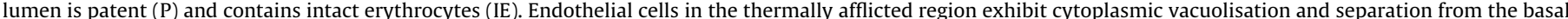

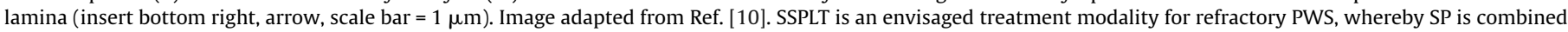

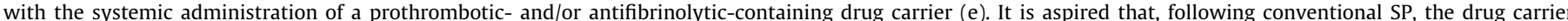

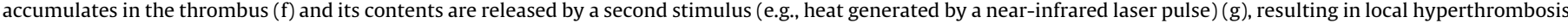

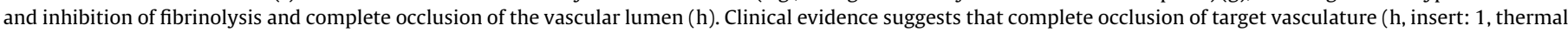
coagulum; 2, thrombus) is associated with well-responding lesions.

The therapeutic efficacy of SP with respect to PWS depends on the extent to which the target vasculature is afflicted by the photothermal response. Complete photocoagulation/occlusion of the vascular lumen is required for optimal lesional clearance [6], which occurs in approximately $40 \%$ of patients [7]. Contrastingly, moderately responding (20-46\%) and recalcitrant (14-40\%) PWS $[7,8]$ exhibit varying degrees of incompletely photocoagulated vessels containing semi-obstructive thermal coagula (Fig. 1a-d). Consequently, alternative treatment strategies are needed to improve therapeutic outcomes in the poorly-to-non-responsive PWS patient population [9].

Recently an experimental modality, site-specific pharmacolaser therapy (SSPLT) [10], was proposed to ameliorate PWS recalcitrance to conventional SP. The conceptual framework of SSPLT is based on the occurrence of a hemodynamic response (thrombosis) following the photothermal response [11-13]. Accordingly, SP is combined with the prior administration of a prothrombotic- and/or antifibrinolytic-containing drug delivery system to instill complete occlusion, and thus complete removal, of semi-photocoagulated target vessels by the pharmacological augmentation of the hemodynamic response (Fig. 1e-h).

The aims of the study were to determine the role and the kinetics of primary and secondary hemostasis in the hemodynamic response and to establish which key platelet surface receptors are involved in SP-induced thrombosis using a hamster dorsal skin fold model in conjunction with fluorescent labeling of platelets and intravital fluorescence microscopy. The findings comprise a basis for the continued development of SSPLT in an effort to optimize the laser treatment of aberrant cutaneous vasculature.

\section{Materials and methods}

1,2-Dipalmitoyl-sn-glycero-3-phosphocholine (DPPC) and 1,2distearoyl-sn-glycero-3-phosphocholine (DSPC) were purchased from Lipoïd (Ludwigshafen, Germany). Polyethylene glycol-conjugated 1,2-distearoyl-sn-glycero-3-phosphoethanolamine (DSPE$\mathrm{PEG}_{2000}$ ) was provided by Genzyme Pharmaceuticals (Liestal, Switzerland). Alexa488-labeled (Molecular Probes, Eugene, OR) rat anti-mouse CD62P monoclonal antibodies (mAbs) (CD62PAlexa488, clone RB40.34) and FITC-conjugated rat anti-mouse $\operatorname{IgG}_{1 \mathrm{k}}$ isotype control (IgG-FITC, clone R3-34) were obtained from Research Diagnostics (Flanders, NJ) and FITC-conjugated $\mathrm{F}\left(\mathrm{ab}^{\prime}\right)_{2}$ fragments of polyclonal rabbit anti-mouse IgG ( Fab $_{2}$-FITC) from Dako Cytomation (Glostrup, Denmark). Mouse anti-human CD42b (clone 11A4) mAbs were cloned as described [14]. 5(6)-Carboxyfluorescein (CF) was acquired from Kodak Chemicals (Williston, VT), heparin Choay from Sanofi Winthrop (Gentilly, France), and fluorescent microspheres (FluoSpheres Red, $\varnothing=1 \mu \mathrm{m}$ ) from Molecular Probes.

Online supplemental material is indicated with a prefix ' $\mathrm{S}$ ' throughout the manuscript.

\subsection{Animals}

The animal protocol was approved by the Lille University Hospital animal ethics committee. Animals were treated in compliance with NIH publication 86-23.

Sixty two male Golden Syrian hamsters (93-117 g, Dépré, Saint Doulchard, France) were anesthetized by intramuscular injection of ketamine (200 mg/kg), xylazine (10 mg/kg), and buprenorfine $(0.02 \mathrm{mg} / \mathrm{kg})$ after pre-anesthesia with diethyl ether. The dorsal chamber, which has been employed previously as a preclinical 
(a)

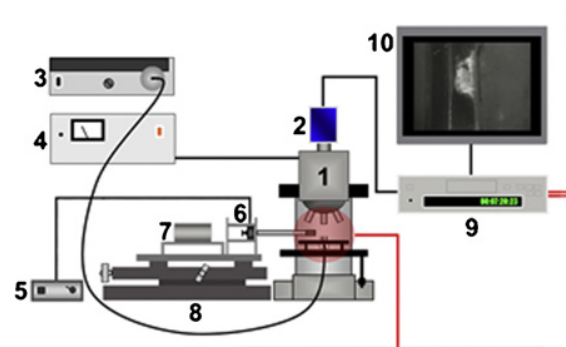

(b)

\section{-CF ANALYSIS (manual contour, 2 independent analysts)}
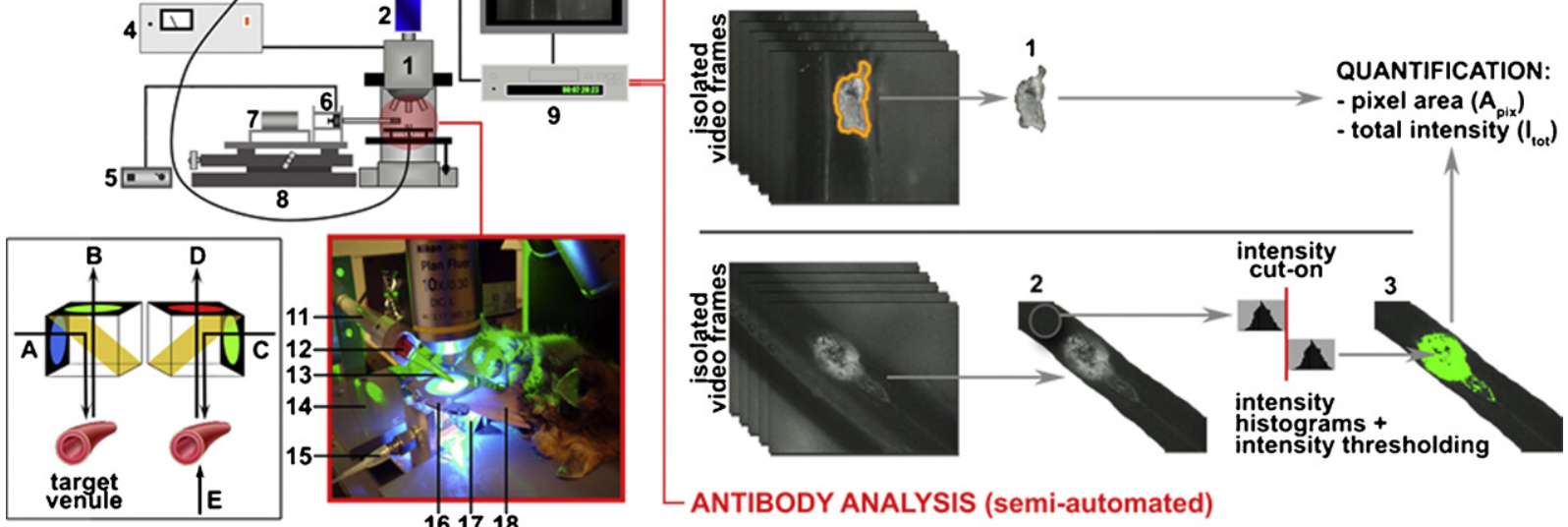

ANTIBODY ANALYSIS (semi-automated)

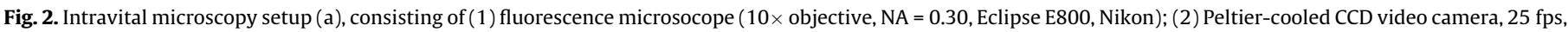

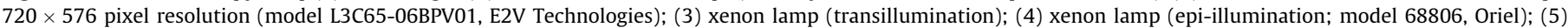

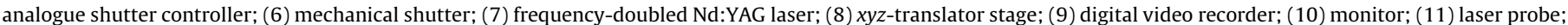

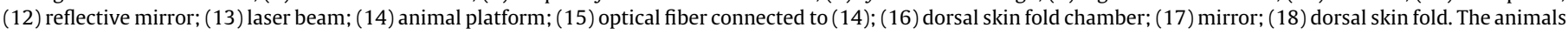

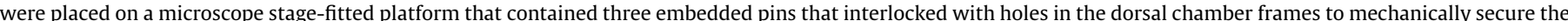

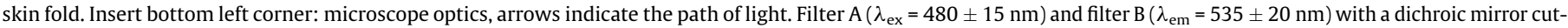

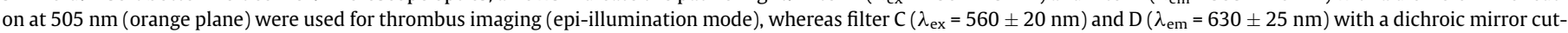

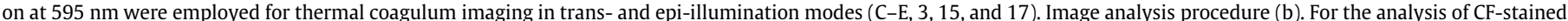

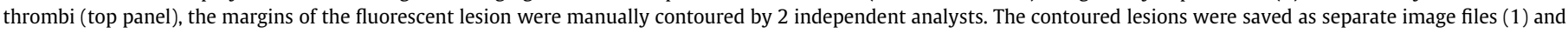

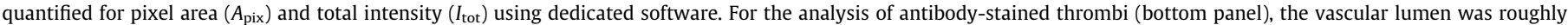

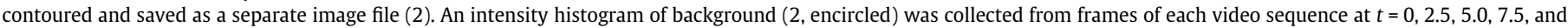

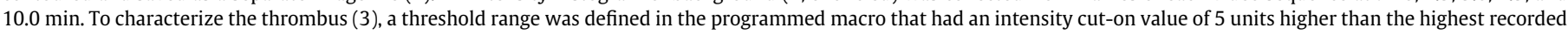

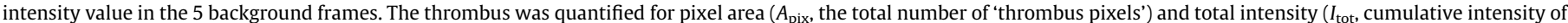

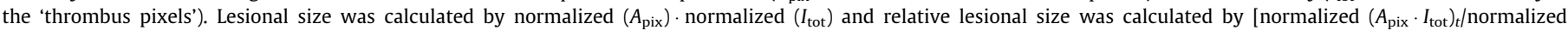
$\left(A_{\text {pix }} \cdot I_{\text {tot }}\right)_{t=0}$ ], where $t$ represents a time point in the video sequence and $t=0$ represents the time point immediately after the laser pulse, defined as baseline.

model for PWS vasculature [15-17], was implanted according to Bezemer et al. [15]. Reagents were infused through the subclavian vein with a $30 \mathrm{G}$ needle $(\sim 200 \mu \mathrm{L} / 30 \mathrm{~s})$. The animals were sacrificed by intravenous administration of potassium chloride.

\subsection{Liposome preparation}

Liposomes $(\varnothing=132 \pm 11 \mathrm{~nm}$, section-S3) composed of DPPC:DSPC:DSPE-PEG 2000 (10:85:5 mole ratio) were loaded with a self-quenching concentration $\mathrm{CF}(100 \mathrm{mmol} / \mathrm{L}$, section-S3) as described previously [18]. Unencapsulated CF was removed by dialysis (Spectra/Por 7, MWCO-100,000, Spectrum Laboratories, Rancho Dominguez, CA) in phosphate buffered saline (PBS) at room temperature (RT) until a residual solvent concentration of $40 \mu \mathrm{mol} / \mathrm{L} \mathrm{CF}$ (measured spectrophotometrically, $\mathrm{OD}_{450}=0.59$ ) was obtained during gentle stirring.

Raising the temperature above the phase transition temperature of the lipid bilayer $\left(55.5^{\circ} \mathrm{C}\right.$, Fig. S1) is associated with a gel-toliquid-crystalline phase transition of component phospholipids, leading to rapid release of $\mathrm{CF}$ and a reduction in fluorescence quenching. Hyperfluorescence during intravital microscopy following the laser pulse therefore served as an indicator for thermal denaturation of plasma components $\left(>45^{\circ} \mathrm{C}\right.$ [19]) and erythrocytes $\left(<51^{\circ} \mathrm{C}[20]\right)$, i.e., precursor events in thermal coagulum formation.

\subsection{Intravital microscopy, laser-induced thrombosis}

The microscopy and thrombus induction setup is explained in Fig. 2a. To verify that non-obstructive thermal coagula (Fig. 1c and d) were formed at the laser parameters employed for thrombus induction, the microscope optics were configured as described previously [15]. Vascular patency was determined by infusion of fluorescent microspheres $\left(2 \times 10^{9}\right.$ microspheres $/ \mathrm{kg}, 100-\mu \mathrm{L}$ injection volume) [15]. Thermal coagula $(n=15)$ were visualized using a filter set whose excitation wavelength range $\left(\lambda_{\text {ex }}=540-\right.$ $580 \mathrm{~nm}$ ) matches a high absorption range of thermally denatured blood [21] and whose emission range $\left(\lambda_{\mathrm{em}}=605-655 \mathrm{~nm}\right)$ is broad enough to generate brightfield images in transillumination mode. In this configuration, simultaneous visualization of the laser-induced thermal coagulum (appearing dark against a lighter background), skin fold anatomy, and fluorescent microspheres (section 'Shear Rates') was possible. For thrombus imaging, mAband CF-labeled platelets were visualized at $\lambda_{\text {ex }}=480 \pm 15 \mathrm{~nm}$ and $\lambda_{\text {em }}=535 \pm 20 \mathrm{~nm}$. In some antibody experiments, transillumination was applied for contrast enhancement. Endovascular events were recorded for a period of $8 \mathrm{~min}$ in the thermal coagulum experiments and for $15 \mathrm{~min}$ in the thrombosis experiments.

\subsection{Intravital platelet labeling}

After implantation of the dorsal skin fold chamber, platelets were stained cytochemically by infusion of $180 \mu \mathrm{L}$ of the liposome suspension $(n=17)$ to study the involvement of primary hemostasis. Resting and activated platelets endocytose free CF [22], infused in unencapsulated form and released from the liposomes, resulting in the formation of a fluorescent thrombus following laser-induced endovascular damage. High molecular weight heparin was administered after liposome infusion at a concentration of $2000 \mathrm{IU} / \mathrm{kg}$ $(n=11)$ to study the involvement of secondary hemostasis.

Platelets were fluorescently immunolabeled by infusion of mouse anti-human CD42b mAbs (350 $\mu \mathrm{g} / \mathrm{kg}, n=10)$ secondarily labeled with Fab $_{2}$-FITC $(250 \mu \mathrm{g} / \mathrm{kg}$ ) during 15 min before infusion to assess the role of glycoprotein (GP)Ib $\alpha$ in the hemodynamic 

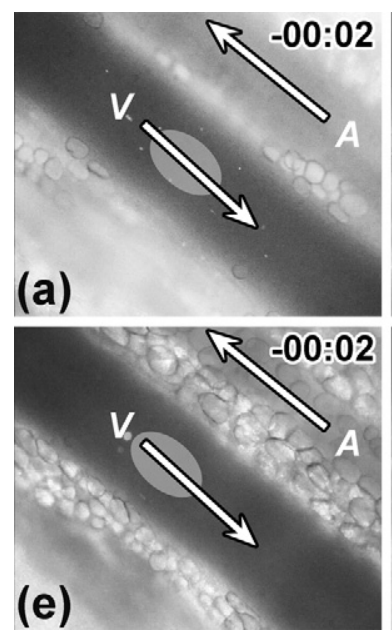
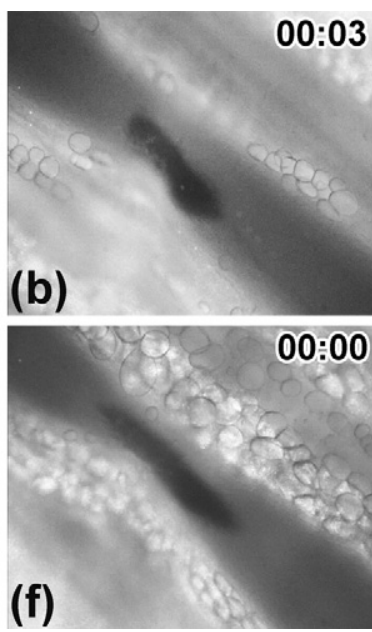
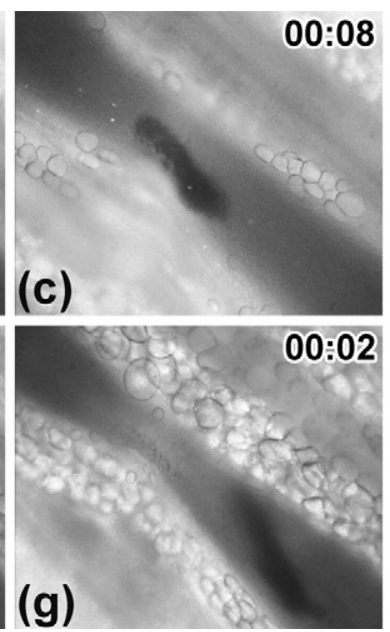
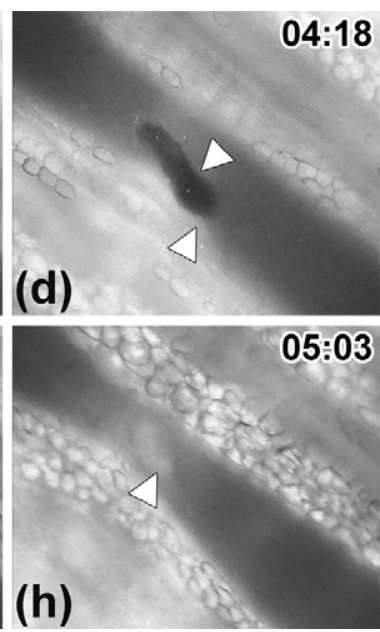

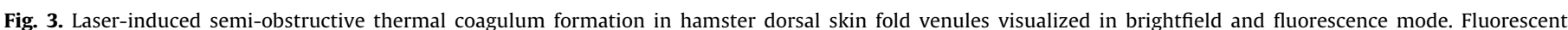

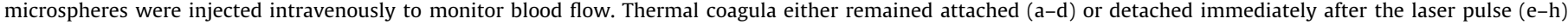

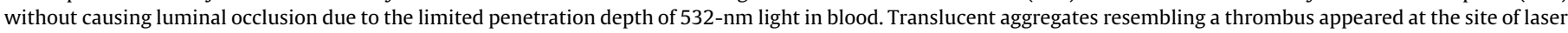

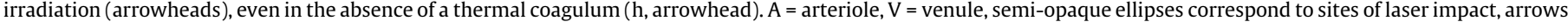
indicate direction of flow, the time relative to the laser pulse is indicated in the upper right corner (min:sec).

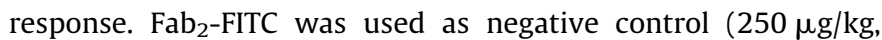
$n=5$ ). Fractional immunoblocking of GPIb $\alpha$ ( $3 \%$ of platelets, section-S5) with fluorescent CD42b mAbs allowed simultaneous visualization and quantification of platelet aggregation under mild inhibitory conditions. The anti-CD42b mAbs exhibited strong cross-reactivity with resting and activated hamster platelets (section-S4), reaching a level of saturation at $\sim 2.5 \mu \mathrm{g} / 10^{6}$ platelets (section-S5), and induced a mild reduction in platelet count (section-S6).
Activated platelets were stained by infusion of CD62PAlexa488 mAbs ( $500 \mu \mathrm{g} / \mathrm{kg}, n=10)$ to assess the role of P-selectin in the hemodynamic response. IgG-FITC (500 $\mu \mathrm{g} / \mathrm{kg}, n=4)$ was used as isotype control to determine the extent of non-specific binding. The anti-CD62P mAbs exhibited cross-reactivity with activated but not resting hamster platelets (section-S4), although some nonspecific binding to resting hamster platelets was observed (Fig. S2). The anti-CD62P mAbs induced negligible reduction in platelet count (section-S6).

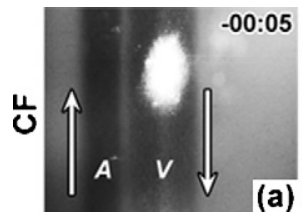

(a)

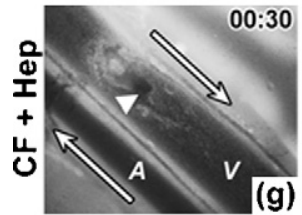

(m)

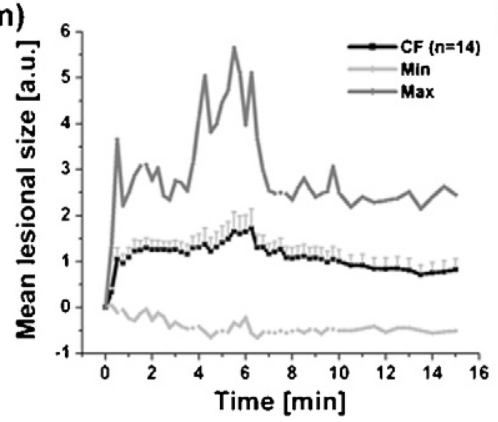

(b)

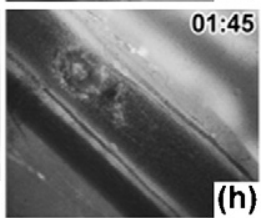

(h)

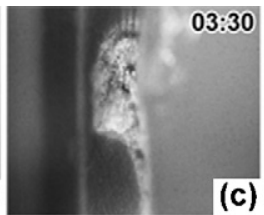

(c)

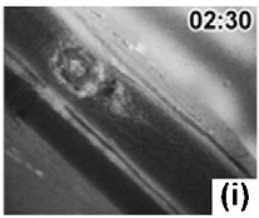

(n)
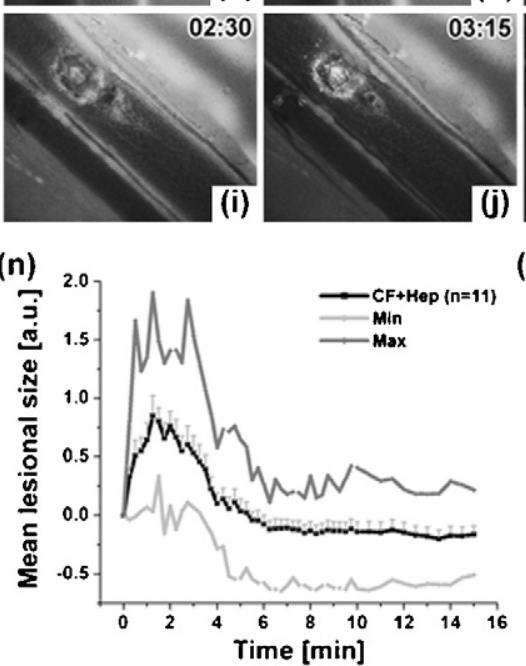

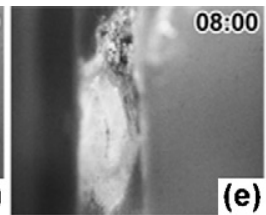

(e)
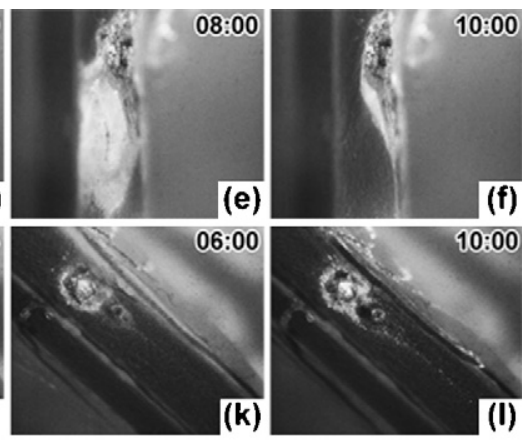

(o)

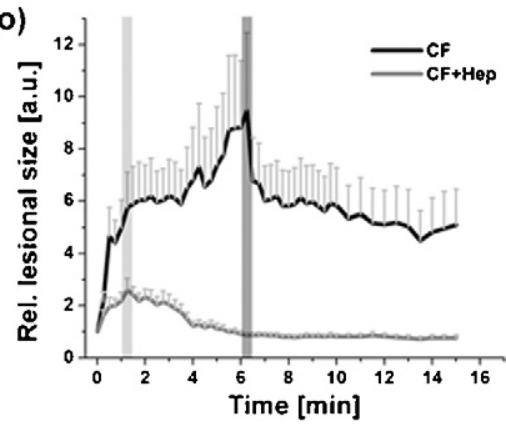

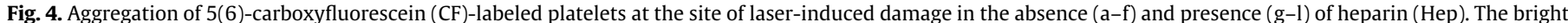

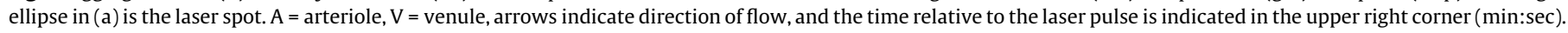

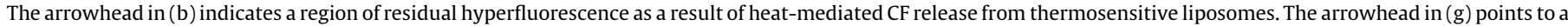

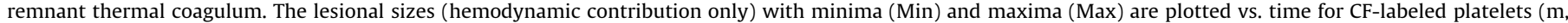

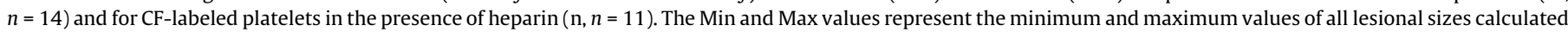

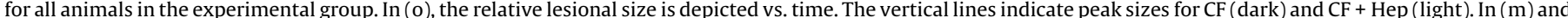

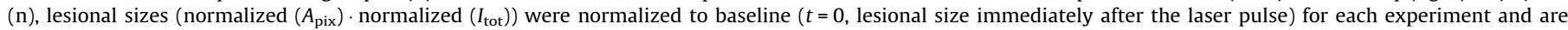
presented as mean \pm SEM per experimental group. 
All mAbs were diluted with $0.9 \%$ sodium chloride solution to a final injection volume of $200 \mu \mathrm{L}$.

\subsection{Laser irradiation}

The target venules had a mean \pm SD diameter of $157 \pm 35 \mu \mathrm{m}$ (range $=86-252 \mu \mathrm{m}$ ). Lesions were induced with a frequencydoubled Nd:YAG laser $(532 \mathrm{~nm}$, Entertainer, Laser Quantum, Cheshire, UK) at a power of $224 \mathrm{~mW}$, a mean \pm SD incident radiant exposure of $289 \pm 38 \mathrm{~J} / \mathrm{cm}^{2}$, a $2.3 \times 10^{-3}-\mathrm{mm}^{2}$ spot size, and a $30-\mathrm{ms}$ pulse duration [15]. The pulse duration for this wavelength falls within the clinically employed range [23].

\subsection{Shear rates}

Blood flow measurements were performed using fluorescent microspheres. Shear rates were determined $(n=95)$ based on the measured blood flow velocity and vessel radius (section-S7). At a mean $\pm S D$ flow of $0.48 \pm 0.21 \mathrm{~mm} / \mathrm{s}$ and a mean $\pm S D$ venular diameter of $0.15 \pm 0.03 \mathrm{~mm}$, the mean $\pm S D$ shear rate was $7.0 \pm 3.7 \mathrm{~s}^{-1}\left(\right.$ range $\left.=1.8-19.6 \mathrm{~s}^{-1}\right)$.

\subsection{Lesion quantification}

The quantification of laser-induced lesions was performed differently for cytochemically (CF-) vs. immunolabeled platelets (Fig. 2b, section-S8). For the former, isolated video frames of laserinduced lesions were manually contoured and quantified for pixel area $\left(A_{\text {pix }}\right)$ and total intensity $\left(I_{\text {tot }}\right)$ in SigmaScan Pro (Systat Software, Point Richmond, CA). Contrastingly, immunolabeled thrombi were demarcated in SigmaScan Pro using a thresholding algorithm, whereby 'thrombus pixels' were defined as pixels with an intensity of 5 grayscale units above the highest background intensity, and quantified for $A_{\text {pix }}$ and $I_{\text {tot }}$. For both quantification techniques, $A_{\mathrm{pix}}$ was normalized to baseline ( $t=0$, lesional area immediately after the laser pulse) and $I_{\text {tot }}$ was normalized to the maximum total intensity.

Lesional size was defined by normalized $\left(A_{\text {pix }}\right) \cdot$ normalized $\left(I_{\text {tot }}\right)$ in both quantification methods and expressed comprehensively (thermal coagulum + thrombus) or individually (thrombus). Normalization of $A_{\text {pix }}$ and $I_{\text {tot }}$ and lesional size calculations were performed per experiment/animal. Lesional sizes were averaged per experimental group, normalized to baseline, and plotted as a function of time. The relative lesional size was calculated by dividing the lesional size at each time interval by the baseline value.

Additionally, a computational analysis method was developed for validating the manual image analysis. Good agreement was found between manual and automated analysis (section-S9).

\subsection{Statistical analysis}

Statistical analysis (means, standard deviations, and independent hetero- and homoscedastic Student's $t$-tests) was performed with SPSS (SPSS, Chicago, IL). Shapiro-Wilk tests confirmed the normal distribution of continuous data. The type of $t$-test used was based on Levene's test of equality of variances. A $p$-value of $\leq 0.05$, designated by $\left({ }^{*}\right)$ throughout the text, was considered statistically significant. A $p$-value of $\leq 0.01$ is designated by $\left.{ }^{* *}\right)$.

\section{Results}

\subsection{Induction of subocclusive thermal coagula}

The laser-induced formation of subocclusive thermal coagula (photothermal response) was investigated first to ensure that our model emulated the endovascular damage profile associated with SP-treated refractory PWS vasculature (Fig. 1d). Laser irradiation consistently resulted in the formation of subocclusive thermal coagula in all irradiated vessels as evidenced by the uninterrupted flow of fluorescent microspheres (Video-S1/S2). Thermal coagula remained attached to the vessel wall (Fig. $3 a-d)$ or detached within a few seconds after the laser pulse (Fig. 3e-h).

\subsection{The photothermal response triggers primary and secondary hemostasis}

Next, the manifestation of primary hemostasis (platelet aggregation) following photothermolysis was studied. Platelets were labeled by the systemic infusion of CF and liposomes containing a self-quenching concentration of CF were co-infused to serve as a thermal damage indicator. Laser irradiation was associated with transient hyperfluorescence as a result of a heat-induced liposomal membrane transition and release of $\mathrm{CF}$ (Fig. 4b, arrowhead, Video-S3), confirming local denaturation of plasma proteins and erythrolysis (thermal coagulum formation).

Platelet adhesion and the development of a nidus occurred in all irradiated venules within seconds after thermal coagulum formation (Fig. 4a-f), which was characterized by a rapid growth phase during the first $1.25 \mathrm{~min}$ and a slow growth phase in the subsequent $5.0 \mathrm{~min}$. At $6.25 \mathrm{~min}$ the comprehensive lesional size reached a maximum with a 9.5 -fold greater volume with respect to baseline (**, Fig. $4 \mathrm{~m}$ and o). The slow growth phase encompassed extensive thromboembolic activity in which clot build-up exceeded breakdown, given the zigzag pattern of the maxima and the upward trend of the lesional size curve, respectively (Fig. $4 \mathrm{~m}$ ). The slow growth phase was ensued by clot breakdown as evidenced by the rapid decline in lesional size after $6.25 \mathrm{~min}$ (Fig. $4 \mathrm{~m}$ and $\mathrm{o}$ ) and extensive embolization of large platelet
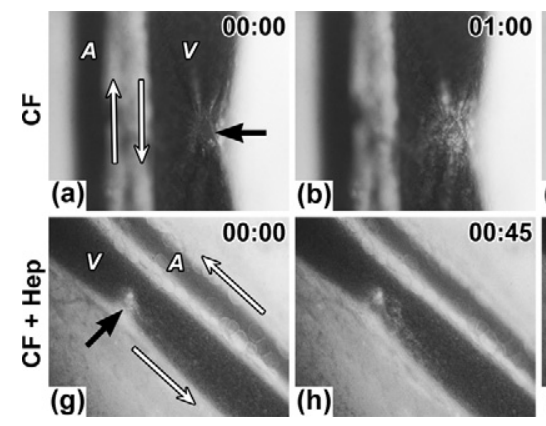
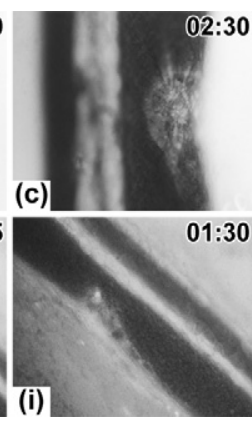
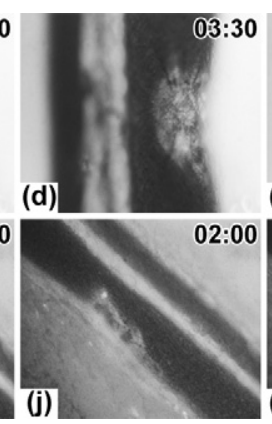

700
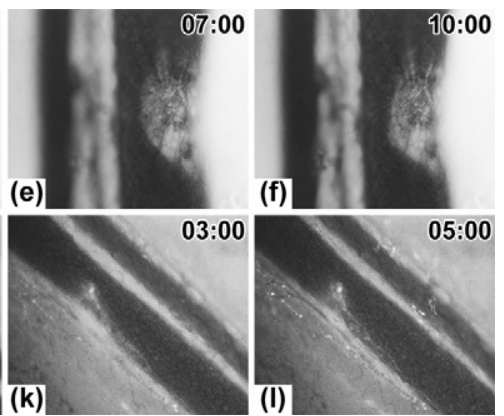

Fig. 5. Laser-induced thrombus formation in the absence (a-f) and presence $(g-l)$ of heparin (Hep) in venules $(V)$ where the thermal coagulum had dislodged. Platelets were fluorescently labeled by the systemic administration of free and liposome-encapsulated 5(6)-carboxyfluorescein (CF). A = arteriole, white arrows indicate direction of flow, black arrows indicate the site of laser irradiation, the time relative to the laser pulse is indicated in the upper right corner (min:sec). 
aggregates (Video-S3). At $15.0 \mathrm{~min}$, the lesions had gradually sloughed off to $58 \%$ of their maximum $\left({ }^{* *}\right)$. Platelet adhesion and aggregation at the site of laser irradiation occurred in the presence and absence of a thermal coagulum (Fig. 5a-f).

Heparin, an antagonist of factor (f)Xa and thrombin formation [24], was infused to determine the involvement of coagulation (secondary hemostasis) (Fig. 4g-1). Heparin reduced the maximum lesional size to $49 \%$ of the heparin-untreated group ( $p=0.07$, Fig. $4 \mathrm{n}$ vs. $m$ ) and caused the peak of thrombosis to occur at 1.25 min (Fig. $4 \mathrm{n}$ and o). At this time point the comprehensive lesional size had increased 2.6-fold (Fig. 4o), whereby the maximum relative lesional size was $27 \%$ of that in the heparinuntreated group $\left({ }^{*}\right)$.

In contrast to the heparin-untreated group, clot breakdown started after $1.25 \mathrm{~min}$ (Fig. 4n) and encompassed extensive embolization of platelet aggregates and, in some instances, portions of the thermal coagulum. The breakdown phase plateaued at $6.25 \mathrm{~min}$ at a lesional size that did not differ from baseline $(p=0.08)$, suggesting that the presence of residual platelet aggregates was minimal and/or that the thermal coagulum had partly or entirely dissociated from the vascular wall. As reported for the heparin-untreated group, the presence of a thermal coagulum was not required for platelet adhesion and aggregation to occur at the site of laser irradiation (Fig. $5 \mathrm{~g}-1$ ).

The accumulation of CF-labeled platelets at the site of endovascular damage and the inhibitory effect of heparin demonstrate that the photothermal response triggers primary as well as secondary hemostasis, respectively, in a thermal-coagulum adhesion/embolization-independent manner. To examine which key platelet receptors are involved in cell adhesion/aggregation during the hemodynamic response, the hemodynamic response was studied following immunoblocking of GPIb $\alpha$ (CD42b) and Pselectin (CD62P).

\subsection{Partial inhibition of $C D 42 b$ reduces the extent of laser-induced thrombosis}

CD42b is a transmembrane subunit of the constitutively expressed GPIb-IX-V receptor complex with heterotypic binding sites for von Willebrand factor (vWF), Mac-1, CD62P, $\alpha-$ thrombin, fXI/XIIa, and high-molecular-weight kininogen [25]. Although the major physiological function of $\mathrm{CD} 42 \mathrm{~b}$ is the adhesion of circulating platelets to vWF in the subendothelial matrix at high shear, which leads to activation of integrin $\alpha_{\text {IIb }} \beta_{\text {III }}$ (GPIIb/IIIa) and subsequent aggregation [26], it has also been shown to mediate platelet adhesion under low shear conditions, i.e., in venules [27,28]. Inhibition of CD42b has further been correlated to significantly reduced platelet microparticle formation [29]. At a shear rate of $7.0 \pm 3.7 \mathrm{~s}^{-1}$ in hamster venules, CD42b may therefore constitute an important receptor during the hemodynamic response, inasmuch as both platelet aggregation and coagulation prevail.

Anti-CD42b mAbs were infused to investigate the role of GPIb $\alpha$ in the hemodynamic response (Fig. 6a-f). Fractional immunoblocking of CD42b imposed no deleterious effect on thrombus formation during the first 3.5 min compared to CF-stained lesions, but significantly reduced clot size during the subsequent $8.0 \mathrm{~min}$ (*, Fig. $6 \mathrm{~m}$ ). Thrombosis peaked at $2.75 \mathrm{~min}$ (Fig. $6 \mathrm{~m}$ and o) followed by a steep deterioration phase, characterized by embolization of platelet aggregates and, sparsely, portions of the thermal coagulum, that stabilized at $4.25 \mathrm{~min}$. Thrombi remained enveloped around the thermal coagulum up to $15.0 \mathrm{~min}$ ( ${ }^{* *}$ vs. baseline, $p=0.09$ vs. CF), suggesting that, at an estimated $3 \%$ GPIb $\alpha$ inhibition, clot fortification by cross-polymerized fibrin imposed greater resistance to deterioration than a clot composed of predominantly platelets (Fig. $6 \mathrm{~m}, \mathrm{CD} 42 \mathrm{~b}$ vs. $\mathrm{CF}+\mathrm{Hep})$.

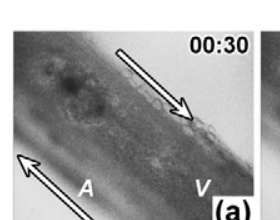

(a)

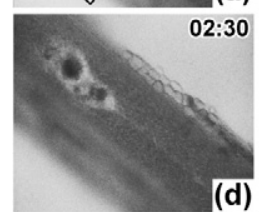

(d)

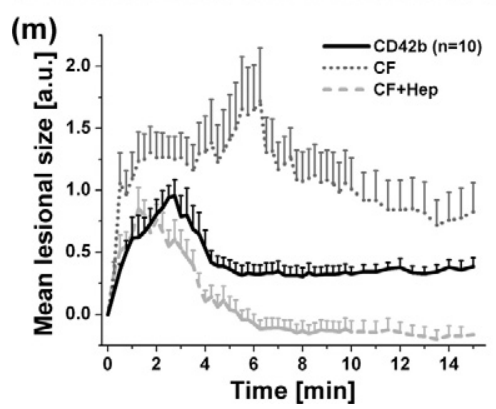

CD42b

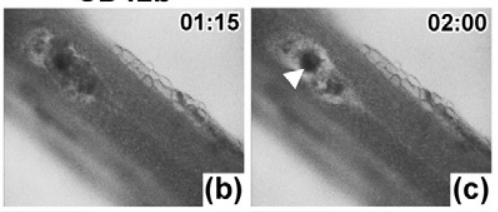

(c)

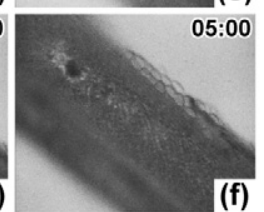

(n)

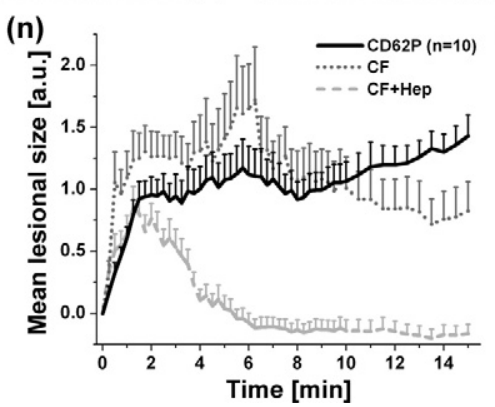

CD62P
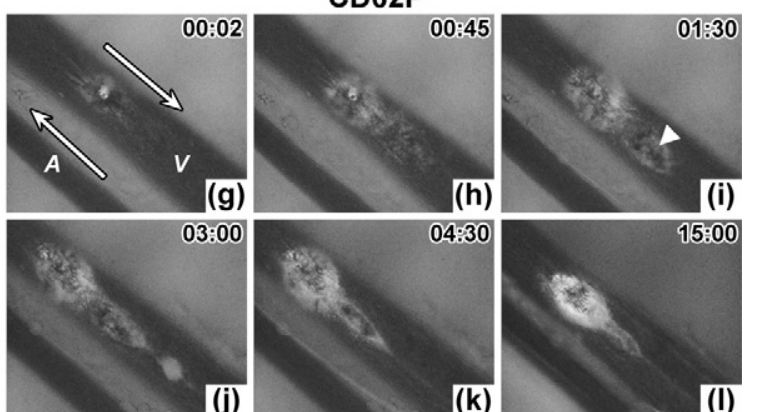

(h)

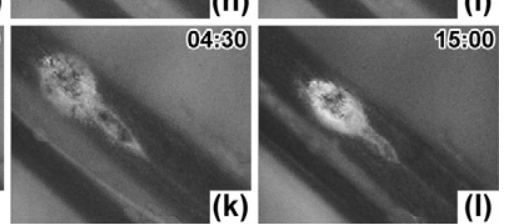

(o)

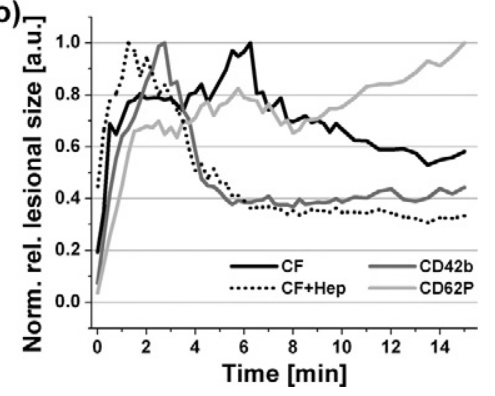

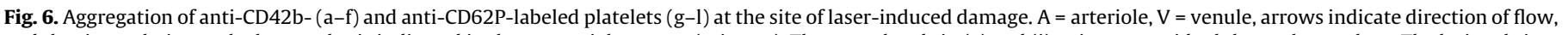

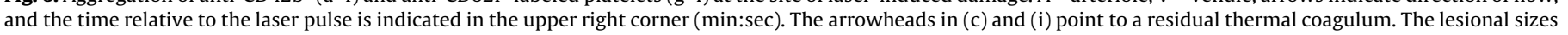

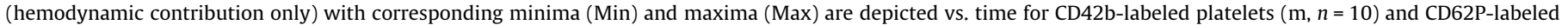

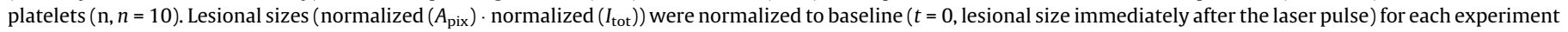

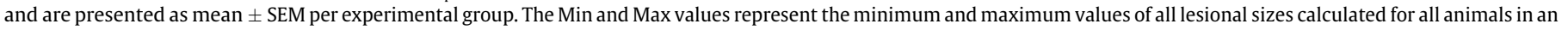

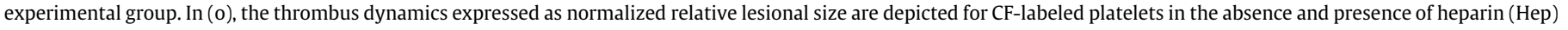
and anti-CD42b- and anti-CD62P-labeled platelets. Mean values were normalized to maximum. 


\subsection{Inhibition of CD62P does not affect the extent of laser-induced thrombosis}

CD62P is a cell adhesion molecule constitutively expressed in platelet $\alpha$-granules [30] and endothelial cell Weibel-Palade bodies [31] that, upon cell activation, is translocated to the outer membrane to mediate platelet-platelet [32], platelet-leukocyte [33], and platelet-endothelial cell interactions [34]. In addition to cell recruitment, the expression of $\mathrm{CD} 62 \mathrm{P}$ potentiates a procoagulant state by enhancing fibrin deposition [35] through the incorporation of P-selectin glycoprotein ligand (PSGL-1)-expressing, tissue factor-bearing microparticles derived from the abovementioned cells [36]. As CD42b, CD62P may therefore play an instrumental role in the laser-induced hemodynamic response.

Anti-CD62P mAbs were infused to assess the role of P-selectin in the hemodynamic response (Fig. 6g-1). With the known inhibitory properties of the RB40.34 clone (section-S4), it was expected that the anti-CD62P mAbs would reduce the extent of thrombosis. Although a slight reduction in thrombus size manifested itself in the rapid growth phase, no inhibitory effect was observed in the slow growth and breakdown phases vs. CFstained thrombi (Fig. 6n, black vs. dotted line, respectively). The maximum thrombus size was reached at $5.75 \mathrm{~min}$ and both lesional size curves (CD42b- and CF-stained thrombi) exhibited a similar progression up to $8.0 \mathrm{~min}$. The 8.0 -min time point marked a deflection in the downward trend in lesional size in the CD62P group, which may have been a result of increased CD62P expression (as evidenced by an increase in fluorescence intensity and not the lesional area, data not shown) and/or the nonspecific binding of the $\mathrm{mAb}$ (section-S4).

\section{Discussion}

A laser-mediated vascular injury model was employed with which the photothermal and hemodynamic response could be concomitantly studied in refractory PWS vessel analogues by intravital fluorescence microscopy. With this model we corroborated that primary hemostasis (platelet aggregation) comprises an integral component of endovascular laser-tissue interactions in semi-photocoagulated blood vessels [11-13]. Additionally, we demonstrated that (1) secondary hemostasis (blood coagulation) is triggered by SP, (2) primary and secondary hemostasis occur in the absence of a thermal coagulum, (3) CD42b is involved in the adhesion of platelets at the site of laser irradiation under low flow conditions, (4) the adhesion of platelets at the site of laser irradiation is accompanied by platelet activation, and (5) CD62P does not mediate platelet adhesion during the hemodynamic response. Moreover, the kinetics of laser-induced thrombosis in low-flow refractory PWS vessel analogues were established. Knowledge about the involved platelet receptor and thrombosis kinetics is particularly important in the continued development of SSPLT as a clinical modality.

As this study demonstrated, an intricate and causal relationship exists between the photothermal and the hemodynamic response. This relationship appears to be manifested at different levels: the nucleation centers (erythrocytes), the endothelium, and the thermal coagulum. Firstly, rapid heat build-up in erythrocytes causes the cells to swell and rupture [11,37]. Erythrocytes contain adenosine diphosphate [38] and phosphatidyl serine [39] that, when liberated and exposed, trigger platelet adhesion [40] and activation [41] and initiation of coagulation [42], respectively. Erythrocyte membrane disruption and complete disintegration have been reported to occur at $47-49^{\circ} \mathrm{C}$ and $50{ }^{\circ} \mathrm{C}$, respectively $[20,37]$. These temperatures were exceeded in the in vivo experiments as corroborated by the CF-encapsulating thermosensitive liposomes and by the consistent formation of thermal coagula at the employed laser settings. Furthermore, it has been shown that ruptured erythrocytes remain attached to the thermal coagulum [43], causing the biochemical template for thrombosis to become stationary following laser irradiation. Image analysis of laser-induced lesions confirmed that thrombo-embolic activity always occurred around the thermal coagulum, even when the thermal coagulum had attached to or was overlaying a nonirradiated portion of the vessel downstream of the irradiation site. Consequently, erythrolysis constitutes an important trigger of the hemodynamic response following the photothermal response. This is underscored by the finding that laser-induced thrombosis in vivo occurs in irradiated blood vessels perfused with washed erythrocytes, erythrocyte ghosts, or hemolysate but not with platelet-rich plasma, PBS, or a non-absorbing exogenous chromophore [12].

Secondly, the heat-afflicted endothelium evidently plays a role in the hemodynamic response. High-fluence laser irradiation of microvessels causes ultrastructural perturbation of the endothelial cell membrane and denudation of the endothelial monolayer $[13,44,45]$, which triggers primary $[46,47]$ and secondary hemostasis [42]. It should be noted that the volumetric heat production, $\mu_{\mathrm{a}} \cdot \phi$, where $\mu_{\mathrm{a}}$ is the absorption coefficient $\left(\mathrm{cm}^{-1}\right)$ and $\phi$ is the fluence rate $\left(\mathrm{J} / \mathrm{cm}^{2}\right)$, that led to such endothelial damage [13] was very high $\left(\sim 17,656 \mathrm{~kJ} / \mathrm{cm}^{3}\right.$, section-S10.1) and not representative for either the clinical setting or our model. However, Tan et al. [44,45], who employed a substantially shorter pulse duration and much larger spot size for treating PWS, showed that endothelial damage can be achieved at significantly lower $\mu_{\mathrm{a}} \cdot \phi$. Contrastingly, at a thousand-fold lower $\mu_{\mathrm{a}} \cdot \phi$ of $\sim 16 \mathrm{~kJ} / \mathrm{cm}^{3}$ (section-S10.2), thermal coagulum formation and endothelial denudation were absent and only one component of the hemodynamic response (platelet adhesion and aggregation) prevailed, albeit transiently [18]. Inasmuch as our model produced a thermal coagulum at a $\mu_{\mathrm{a}} \cdot \phi$ of $\sim 66 \mathrm{~kJ} / \mathrm{cm}^{3}$ at the blood-endothelium interface (sectionS10.3), a contribution of thermally afflicted endothelium to the hemodynamic response is warranted. This was experimentally corroborated by the fact that thrombosis occurred in laserirradiated vessel segments where the thermal coagulum had dislodged (e.g., Fig. 3h, Video-S2) and is in agreement with previous reports [12].

Thirdly, photocoagulation is associated with protein denaturation $[48,49]$ that embodies conformational rearrangements and cross-linking/aggregation of unfolded/misfolded proteins [50] and corollary amyloid fibril formation [51]. There is increasing evidence that misfolded proteins/amyloids activate platelets via CD42b [52] and initiate the contact activation pathway through the auto-activation of fXII by anionic surfaces [53]. Inasmuch as thermal coagula are in part comprised of thermally denatured (unfolded/misfolded) proteins and anionic moieties exposed on the surface of ruptured erythrocytes, these laser-induced lesions may constitute the basis for the initiation of primary and secondary hemostasis that persisted around the thermal coagula. These postulations are, however, hypothetical and are currently being investigated in a separate study.

Although several specific pathways underlying endovascular laser-tissue interactions require further elucidation, it is unequivocal that SP affects both primary and secondary hemostasis in semi-photocoagulated vasculature. Primary hemostasis involves platelet adhesion, activation, and aggregation. The immunostaining experiments with anti-CD42b and anti-CD62P mAbs revealed that platelet adhesion to the thermal coagulum and/or to the thermally afflicted vascular wall is mediated by GPIb $\alpha$, but not CD62P, and that the platelets become activated upon adhesion, respectively. For platelet aggregation, integrin $\alpha_{\text {IIb }} \beta_{\text {III }}$ (CD41) activation is required [54], which could not be studied directly because none of the assayed antibodies cross-reacted with hamster $\alpha_{\text {IIb }} \beta_{\text {III }}$. Nevertheless, experimental data confirms the activation of integrin 
$\alpha_{\text {IIb }} \beta_{\text {III }}$, and thus aggregation, in the hemodynamic response. Strong evidence is provided by the facts that a $>9$-fold expansion of the thrombus following laser irradiation cannot be accounted for by solely platelet adhesion and that embolization of large platelet aggregates was observed in the breakdown phase. The involvement of GPIb $\alpha$ in the adhesion process further implies activation of integrin $\alpha_{\text {IIb }} \beta_{\text {III }}$ (concurs with the binding of ligands to the GPIb-IX$\mathrm{V}$ complex during platelet adhesion [55]), which was supported by the reduction in thrombus growth following partial immunoneutralization of GPIb $\alpha$. Also, $\alpha_{\text {IIb }} \beta_{\text {III }}$ activation was corroborated by the positive immunolabeling of CD62P that is co-expressed when $\alpha_{\text {IIb }} \beta_{\text {III }}$ is activated [56]. Finally, we performed the same experiments in the dorsal vasculature of 3 surplus BALB/c mice (where anti-CD41 antibodies do cross-react with the respective platelet epitope), and confirmed $\alpha_{\text {IIb }} \beta_{\text {III }}$ activation during laserinduced thrombosis (Video-S4).

During secondary hemostasis, prothrombin is converted to thrombin by the prothrombinase complex, which exerts pleiotropic effects on both platelets and coagulation. The binding of thrombin to the GPIb-IX-V complex induces platelet adhesion and spreading, dense granule secretion, and $\alpha_{\mathrm{II}} \beta_{\mathrm{III}}$ activation and subsequent aggregation [57]. It also accelerates the hydrolysis of protease-activated receptor (PAR)-1 (a thrombin receptor) [58] that further contributes to platelet activation. With respect to coagulation, thrombin mediates the cross-polymerization of fibrin that acts as a support matrix in thrombus fortification. The complete inhibition of thrombin generation at high heparin concentrations did not completely abrogate thrombus formation but substantially reduced the extent and duration of thrombosis. These observations confirm the involvement of the previously mentioned primary hemostasis mechanisms, which do not require thrombin, and attest to a role of coagulation in the hemodynamic response.

Inasmuch as thrombin generation is antagonized by heparin at the level of fXa in the common pathway, it is impossible to deduce whether coagulation was initiated through the tissue factor pathway or the contact activation pathway. The activation of coagulation in our model is, however, in contrast with previous studies $[11,13,59]$, where no fibrin cross-polymerization (secondary hemostasis) was found following laser-induced thrombosis. It should be stressed, however, that the influence of secondary hemostasis was considerably inferior to that of primary hemostasis given that very mild inhibition of $C D 42 b$ and complete inhibition of thrombin formation generated comparable thrombus kinetics curves. This is quite surprising given the fact that venous thrombosis predominantly entails activation of coagulation rather than platelet aggregation [60]. Unfortunately, the lack of mouse anti-human fibrin mAb cross-reactivity with hamster fibrin (section-S4) precluded the intravital qualification and quantification of fibrin cross-polymerization in the thrombi.

In conclusion, the hemodynamic response ensues the photothermal response and involves the activation of primary and, to a lesser extent, secondary hemostasis. Laser-induced venular thrombi reach a maximum size at 6.25 min after laser irradiation under very low flow conditions. Primary hemostasis, encompassing platelet adhesion, activation, and aggregation, is mediated by constitutively expressed GPIb $\alpha$ but not by activation-dependent Pselectin.

\section{Funding sources}

This work was partially supported by the Technological Collaboration Grant (TSGE 1048) of the Dutch Ministry of Economic Affairs (MH, JFB), a grant from Novo Nordisk Farma $\mathrm{BV}(\mathrm{MH})$, and the Bloodomics project (6th Framework Program of the European Union (LSHM-CT-2004-503485)) (IIS, HD). A patent has been filed for the proposed technology (PCT 2010050833).

\section{Acknowledgements}

We thank Bruno Buys for technical support with the laser system, Nathalie Jouy for cross-reactivity analysis, the (biotechnical) staff at KULAK for peri-orbital blood drawing, and Mies Steenbergen for assistance with the DSC.

\section{Appendix A. Supplementary data}

Supplementary data associated with this article can be found, in the online version, at doi:10.1016/j.jdermsci.2011.04.015.

\section{References}

[1] Leffell DJ, Thompson JT. Lasers in dermatology and ophthalmology. Dermatol Clin 1992;10:687-700.

[2] Anderson RR, Parrish JA. Selective photothermolysis: precise microsurgery by selective absorption of pulsed radiation. Science 1983;220:524-7.

[3] Dierickx CC, Casparian JM, Venugopalan V, Farinelli WA, Anderson RR. Thermal relaxation of port-wine stain vessels probed in vivo: the need for 1-10millisecond laser pulse treatment. J Invest Dermatol 1995;105:709-14.

[4] Selim MM, Kelly KM, Nelson JS, Wendelschafer-Crabb G, Kennedy WR, Zelickson BD. Confocal microscopy study of nerves and blood vessels in untreated and treated port wine stains: preliminary observations. Dermatol Surg 2004;30:892-7.

[5] Braverman IM. The cutaneous microcirculation. J Investig Dermatol Symp Proc 2000;5:3-9.

[6] Fiskerstrand EJ, Svaasand LO, Kopstad G, Ryggen K, Aase S. Photothermally induced vessel-wall necrosis after pulsed dye laser treatment: lack of response in port-wine stains with small sized or deeply located vessels. J Invest Dermatol 1996;107:671-5.

[7] Greve B, Raulin C. Prospective study of port wine stain treatment with dye laser: comparison of two wavelengths ( $585 \mathrm{~nm}$ vs. $595 \mathrm{~nm}$ ) and two pulse durations (0. 5 milliseconds vs. 20 milliseconds). Lasers Surg Med 2004;34:168-73.

[8] Hohenleutner U, Hilbert M, Wlotzke U, Landthaler M. Epidermal damage and limited coagulation depth with the flashlamp-pumped pulsed dye laser: a histochemical study. J Invest Dermatol 1995;104:798-802.

[9] Heger M, Bezemer R, Huertas-Pérez JF, Dekker H, Beek JF. Endovascular lasertissue interactions redefined: shining light on novel windows of therapeutic opportunity beyond selective photothermolysis. Photomed Laser Surg 2010;28:569-72.

[10] Heger M, Beek JF, Moldovan NI, van der Horst CM, van Gemert MJ. Towards optimization of selective photothermolysis: prothrombotic pharmaceutical agents as potential adjuvants in laser treatment of port wine stains. A theoretical study. Thromb Hemost 2005;93:242-56.

[11] Hovig T, McKenzie FN, Arfors KE. Measurement of the platelet response to laser-induced microvascular injury. Ultrastructural studies. Thromb Diath Hemorrh 1974;32:695-703.

[12] Wiedeman MP. Vascular reactions to laser in vivo. Microvasc Res 1974;8:1328.

[13] Kovács IB, Tigyi-Sebes A, Trombitás K, Görög P. Evans blue: an ideal energyabsorbing material to produce intravascular microinjury by HE-NE gas laser. Microvasc Res 1975; 10:107-24.

[14] Cauwenberghs N, Vanhoorelbeke K, Vauterin S, Westra DF, Romo G, Huizinga EG, et al. Epitope mapping of inhibitory antibodies against platelet glycoprotein Ibalpha reveals interaction between the leucine-rich repeat N-terminal and C-terminal flanking domains of glycoprotein Ibalpha. Blood 2001;98:65260.

[15] Bezemer R, Heger M, van den Wijgaard JP, Mordon SR, van Gemert MJ, Beek JF. Laser-induced (endo)vascular photothermal effects studied by combined brightfield and fluorescence microscopy in hamster dorsal skin fold venules. Opt Express 2007; 15:8493-506.

[16] Babilas P, Shafirstein G, Bäumler W, Baier J, Landthaler M, Szeimies RM, et al. Selective photothermolysis of blood vessels following flashlamp-pumped pulsed dye laser irradiation: in vivo results and mathematical modelling are in agreement. J Invest Dermatol 2005;125:343-52.

[17] Jia W, Sun V, Tran N, Choi B, Liu SW, Mihm Jr MC, et al. Long-term blood vessel removal with combined laser and topical rapamycin antiangiogenic therapy: implications for effective port wine stain treatment. Lasers Surg Med 2010;42:105-12.

[18] Mordon S, Begu S, Buys B, Tourne-Peteilh C, Devoisselle JM. Study of platelet behavior in vivo after endothelial stimulation with laser irradiation using fluorescence intravital videomicroscopy and PEGylated liposome staining. Microvasc Res 2002;64:316-25. 
[19] Takeda K, Wada A, Yamamoto K, Moriyama Y, Aoki K. Conformational change of bovine serum albumin by heat treatment. J Protein Chem 1989;8:653-9.

[20] Nilsson AM, Lucassen GW, Verkruysse W, Andersson-Engels S, van Gemert MJ. Changes in optical properties of human whole blood in vitro due to slow heating. Photochem Photobiol 1997;65:366-73.

[21] Barton JK, Frangineas G, Pummer H, Black JF. Cooperative phenomena in twopulse, two-color laser photocoagulation of cutaneous blood vessels. Photochem Photobiol 2001;73:642-50.

[22] Heger M, Salles II, van Vuure W, Deckmyn H, Beek JF. Fluorescent labeling of platelets with polyanionic fluorescein derivatives. Anal Quant Cytol Histol 2009;31:227-33.

[23] Lorenz S, Scherer K, Wimmershoff MB, Landthaler M, Hohenleutner U. Variable pulse frequency-doubled Nd:YAG laser versus flashlamp-pumped pulse dye laser in the treatment of port wine stains. Acta Derm Venereol 2003;83:210-3.

[24] Björk I, Lindahl U. Mechanism of the anticoagulant action of heparin. Mol Cell Biochem 1982:48:161-82.

[25] Berndt MC, Shen Y, Dopheide SM, Gardiner EE, Andrews RK. The vascular biology of the glycoprotein Ib-IX-V complex. Thromb Hemost 2001;86:178-88.

[26] Andrews RK, López JA, Berndt MC. Molecular mechanisms of platelet adhesion and activation. Int J Biochem Cell Biol 1997;29:91-105.

[27] Kulkarni S, Dopheide SM, Yap CL, Ravanat C, Freund M, Mangin P, et al. A revised model of platelet aggregation. J Clin Invest 2000;105:783-91.

[28] André P, Denis CV, Ware J, Saffaripour S, Hynes RO, Ruggeri ZM, et al. Platelets adhere to and translocate on von Willebrand factor presented by endothelium in stimulated veins. Blood 2000;96:3322-8.

[29] Pontiggia L, Steiner B, Ulrichts H, Deckmyn H, Forestier M, Beer JH. Platelet microparticle formation and thrombin generation under high shear are effectively suppressed by a monoclonal antibody against GPIba. Thromb Hemost 2006;96:774-80.

[30] Stenberg PE, McEver RP, Shuman MA, Jacques YV, Bainton DF. A platelet alphagranule membrane protein (GMP-140) is expressed on the plasma membrane after activation. J Cell Biol 1985;101:880-6.

[31] Bonfanti R, Furie BC, Furie B, Wagner DD. PADGEM (GMP140) is a component of Weibel-Palade bodies of human endothelial cells. Blood 1989;73:1109-12.

[32] Romo GM, Dong JF, Schade AJ, Gardiner EE, Kansas GS, Li CQ, et al. The glycoprotein Ib-IX-V complex is a platelet counterreceptor for P-selectin. J Exp Med 1999;190:803-14.

[33] Norman KE, Moore KL, McEver RP, Ley K. Leukocyte rolling in vivo is mediated by P-selectin glycoprotein ligand-1. Blood 1995;86:4417-21.

[34] Frenette PS, Denis CV, Weiss L, Jurk K, Subbarao S, Kehrel B, et al. P-selectin glycoprotein ligand 1 (PSGL-1) is expressed on platelets and can mediate platelet-endothelial interactions in vivo. J Exp Med 2000;191:1413-22.

[35] Palabrica T, Lobb R, Furie BC, Aronovitz M, Benjamin C, Hsu YM, et al. Leukocyte accumulation promoting fibrin deposition is mediated in vivo by $\mathrm{P}$ selectin on adherent platelets. Nature 1992;359:848-51.

[36] Furie B, Furie BC. Role of platelet P-selectin and microparticle PSGL-1 in thrombus formation. Trends Mol Med 2004;10:171-8.

[37] Tan OT, Morelli JG, Whitaker D, Boll J, Murphy G. Ultrastructural changes in red blood cells following pulsed irradiation in vitro. J Invest Dermatol 1989;92:100-4.

[38] van Wijk R, van Solinge WW. The energy-less erythrocyte is lost: erythrocyte enzyme abnormalities of glycolysis. Blood 2005;106:4034-42.

[39] Bratosin D, Mazurier J, Tissier JP, Slomianny C, Estaquier J, Russo-Marie F, et al Molecular mechanisms of erythrophagocytosis. Characterization of the senescent erythrocytes that are phagocytized by macrophages. C R Acad Sci III 1997;320:811-8.
[40] Begent N, Born GV. Growth rate in vivo of platelet thrombi, produced by iontophoresis of $\mathrm{ADP}$, as a function of mean blood flow velocity. Nature 1970;227:926-30.

[41] Puri RN, Colman RW. ADP-induced platelet activation. Crit Rev Biochem Mol Biol 1997:32:437-502.

[42] Dahlbäck B. Blood coagulation. Lancet 2000;355:1627-32.

[43] Black JF, Barton JK. Chemical and structural changes in blood undergoing laser photocoagulation. Photochem Photobiol 2004;80:89-97.

[44] Tan OT, Carney JM, Margolis R, Seki Y, Boll J, Anderson RR, et al. Histologic responses of port-wine stains treated by argon, carbon dioxide, and tunable dye lasers. A preliminary report. Arch Dermatol 1986;122:1016-22.

[45] Tan OT, Whitaker D, Garden JM, Murphy G. Pulsed dye laser $(577 \mathrm{~nm}$ ) treatment of portwine stains: ultrastructural evidence of neovascularization and mast cell degranulation in healed lesions. J Invest Dermatol 1988;90:3958.

[46] Spaet TH, Erichson RB. The vascular wall in the pathogenesis of thrombosis Thromb Diath Hemorrh Suppl 1966;21:67-86.

[47] Arfors KE, Dhall DP, Engeset J, Hint H, Matheson NA, Tagen O. Biolaser endothelial trauma as a means of quantifying platelet activity in vivo. Nature 1968;218:887-8.

[48] Thomsen S. Pathologic analysis of photothermal and photomechanical effects of laser-tissue interactions. Photochem Photobiol 1991;53:825-35.

[49] Heger M, Beek JF, Stenback K, Faber D, van Gemert M, Ince C. Darkfield orthogonal polarized spectral imaging for studying endovascular laser-tissue interactions in vivo - a preliminary study. Opt Express 2005;13:702-15.

[50] San Biagio PL, Martorana V, Emanuele A, Vaiana SM, Manno M, Bulone D, et al. Interacting processes in protein coagulation. Proteins 1999;37:116-20.

[51] Chiti F, Dobson CM. Protein misfolding, functional amyloid, and human disease. Annu Rev Biochem 2006;75:333-66.

[52] Herczenik E, Bouma B, Korporaal SJ, Strangi R, Zeng Q, Gros P, et al. Activation of human platelets by misfolded proteins. Arterioscler Thromb Vasc Biol 2007;27:1657-65.

[53] Maas C, Govers-Riemslag JW, Bouma B, Schiks B, Hazenberg BP, Lokhorst HM, et al. Misfolded proteins activate factor XII in humans, leading to kallikrein formation without initiating coagulation. J Clin Invest 2008;118: 3208-18.

[54] Nesbitt WS, Kulkarni S, Giuliano S, Goncalves I, Dopheide SM, Yap CL, et al. Distinct glycoprotein Ib/V/IX and integrin alpha IIbbeta 3-dependent calcium signals cooperatively regulate platelet adhesion under flow. J Biol Chem 2002;277:2965-72.

[55] Asazuma N, Ozaki Y, Satoh K, Yatomi Y, Handa M, Fujimura Y, et al. Glycoprotein Ib-von Willebrand factor interactions activate tyrosine kinases in human platelets. Blood 1997;90:4789-98.

[56] Andrews RK, Berndt MC. Platelet physiology and thrombosis. Thromb Res 2004; 114:447-53

[57] Adam F, Guillin MC, Jandrot-Perrus M. Glycoprotein Ib-mediated platelet activation. A signaling pathway triggered by thrombin. Eur J Biochem 2003:270:2959-70.

[58] De Candia E, Hall SW, Rutella S, Landolfi R, Andrews RK, De Cristofaro R. Binding of thrombin to glycoprotein Ib accelerates the hydrolysis of Par-1 on intact platelets. J Biol Chem 2001;276:4692-8.

[59] Povlishock JT, Rosenblum WI. Injury of brain microvessels with a helium-neon laser and Evans blue can elicit local platelet aggregation without endothelial denudation. Arch Pathol Lab Med 1987;111:415-21.

[60] Strachan L, Gaffney PJ, Scully MF, Kakkar VV. An experimental model for the study of venous thrombosis in vivo. Thromb Res 1974;5:235-42. 